BMJ Paediatrics Open

\title{
Long-term sequelae secondary to snakebite envenoming: a single centre retrospective study in a Costa Rican paediatric hospital
}

Helena Brenes-Chacon (D) ,1,2 Jose M Gutierrez, ${ }^{3}$ Kattia Camacho-Badilla,, ${ }^{1,2}$ Alejandra Soriano-Fallas, ${ }^{1,2}$ Rolando Ulloa-Gutierrez (D) , ${ }^{1,2}$ Kattia Valverde, ${ }^{1,2}$ María Luisa Avila-Aguero (1) ${ }^{1,2}$

To cite: Brenes-Chacon $\mathrm{H}$, Gutierrez JM,

Camacho-Badilla $\mathrm{K}$, et al. Longterm sequelae secondary to snakebite envenoming: a single centre retrospective study in a Costa Rican paediatric hospital. BMJ Paediatrics Open 2020;4:e000735. doi:10.1136/ bmjpo-2020-000735

Received 15 May 2020 Revised 13 August 2020 Accepted 17 August 2020
Check for updates

(c) Author(s) (or their employer(s)) 2020. Re-use permitted under CC BY-NC. No commercial re-use. See rights and permissions. Published by BMJ.

${ }^{1}$ Universidad de Ciencias Medicas (UCIMED), San Jose, Costa Rica

${ }^{2}$ Caja Costarricense del Seguro Social (CCSS), Pediatric Infectious Diseases, Hospital Nacional de Niños "Dr. Carlos Saenz Herrera", San Jose, Costa Rica

${ }^{3}$ Universidad de Costa Rica Instituto Clodomiro Picado, San Jose, Costa Rica

Correspondence to Dr María Luisa Avila-Aguero; avilaaguero@gmail.com

\section{ABSTRACT}

Objectives Although devastating acute effects associated with snake envenoming are well described, the long-term sequelae resulting from these envenomings have not been adequately addressed, especially in the paediatric population. The aim of our study is to describe the clinical characteristics among paediatric patients in Costa Rica who developed long-term sequelae secondary to snakebite envenoming.

Design Retrospective descriptive study of paediatric patients under 13 years who were admitted with a history of a recent snakebite at the National Children's Hospital in Costa Rica from January 2001 to December 2014.

Results We enrolled 74 patients admitted to our centre due to envenoming, and separated those who did not develop sequelae (50 patients) from those who did (24 patients). Of those who presented acute complications during hospitalisation, local wound infection and clinically diagnosed compartmental syndrome were significantly higher in the group that developed sequelae thereafter. Hypertrophic scars $(66.7 \%)$, functional limitation of affected limb (37.5\%) and the need of skin graft (37.5\%) were the most common sequelae. The median follow-up of patients with long-term sequelae after discharge was 25.4 months (5.6-59.4). No deaths were reported during this time period.

Conclusions Given the high economic, personal and healthcare burden that entails follow-up of these patients, efforts should be carried out to prevent the factors associated with sequelae among the affected population.

\section{INTRODUCTION}

Snakebite envenoming is an important cause of morbidity and mortality on a global basis, particularly in sub-Saharan Africa, Asia and Latin America. ${ }^{1}$ It affects $1.8-2.7$ million people worldwide every year, causing between 81000 and 138000 deaths. ${ }^{1}$ Recognised in 2017 as a Neglected Tropical Disease by the $\mathrm{WHO},{ }^{2}$ the actual burden of this disease is still unrecognised. The WHO has launched a global strategy for the prevention and control of these envenomings, ${ }^{2}$ but there is still a

\section{What is known about the subject?}

The WHO estimates that about 5 million snakebites occur each year, resulting in up to 138000 deaths.

- Almost 400000 people suffering snakebite envenoming are left with physical and psychological sequelae and permanent disabilities. Most of this information is based on studies carried out with adult populations.

- There is limited knowledge on relevant aspects of envenomings. The incidence of physical disabilities from envenomings is limited, and the scarce data are mainly focused on adults.

\section{What this study adds?}

- Infection and compartment syndrome after envenoming were the clinical factors most associated with long-term sequelae development.

- Hypertrophic scars, functional limitation of affected limb and the need for skin graft were the most common sequelae.

lot to be known in the follow-up of affected patients.

Although devastating acute effects associated with snakebite envenoming are well described, the long-term sequelae resulting from these envenomings have not been adequately addressed, especially in the paediatric population. ${ }^{3}$ Many studies have described the epidemiological characteristics and clinical profiles of these envenomings, both in adults and children. However, few have focused on the risk factors associated with morbidity and further complications. ${ }^{4}$ The few studies carried out on sequelae following snakebites have identified several physical and psychological outcomes which exert a heavy impact in the quality of life of affected people. ${ }^{5}$ 
It is relevant to further analyse the sequelae that develop as a consequence of snakebite envenomings in various regions of the world. The aim of our study is to describe the clinical characteristics occurring among paediatric patients in Costa Rica who developed longterm sequelae secondary to snakebite envenoming, and provide a general overview of their outcomes.

\section{PATIENTS AND METHODS}

\section{Study design}

Retrospective descriptive study of paediatric patients under 13 years admitted with a discharge diagnosis of a recent snakebite envenoming and who were enrolled at the National Children's Hospital in Costa Rica during a period of 14 years: from January 2001 to December 2014. Patients were identified following International Classification of Diseases-10 diagnosis of discharge provided by the statistic department. The National Children's Hospital is the only tertiary paediatric referral academic hospital in the country. For snake envenomings, patients in need of specialised care (such as general surgery, reconstructive surgery, orthopaedic or infectious diseases evaluations) are the ones referred to our centre. Most of the patients included in this cohort were transferred in the first 24 hours after the event, mainly from regional hospitals in Costa Rica.

All patients admitted during the time period at this health centre were enrolled, and we collected demographic and clinical information, including: (a) time of first medical evaluation; (b) previous medical support provided; (c) antivenom administration; (d) clinical signs and symptoms on admission and (e) acute and long-term complications. Acute complications were defined as complications related to the event that presented during hospitalisation, such as infections, compartmental syndrome, acute bleeding, respiratory and renal abnormalities, and serum sickness, among others, were collected. Long-term complications or sequelae were defined as the presence of a condition also related to the snakebite episode, that requires long-term medical follow-up. Scar complications, functional limitation and deformity among others, were included as long-term sequelae. They were not necessarily present at discharge and could develop along time.

For those who developed long-term sequelae, the follow-up time was also recorded. Severity of envenoming was classified as mild, moderate and severe, according with the clinical manifestations on admission (table 1).

Because of the retrospective nature of this research, patients and public were not involved in the design, or conduct, or reporting, or dissemination plans of this research.

\section{Statistical analysis}

Patients were classified in two groups: those with and those without long-term sequelae. Continuous variables are presented as medians (25th-75th IQR) or means \pm SD according to data distribution, and the groups were compared using either Mann-Whitney or Student's t-test, respectively. Categorical variables are presented as frequencies and compared using the Fisher's exact or $\chi^{2}$ tests.

All analyses were conducted using GraphPad Prism V.8 (GraphPad Software), with a two-sided $p$ value $<0.05$ considered statistically significant.

\section{Patient and public involvement statement}

As a retrospective study, patients were not involved in the recruitment and conduct of this study.

\section{RESULTS \\ Demographic characteristics of patients}

From 2001 to 2014 we enrolled 74 patients admitted to our centre due to acute snakebite envenoming, all caused by viperid snake species, most of these by Bothrops asper. Patients were separated in two groups: those who did not develop sequelae as a consequence of envenoming (50 patients) and those who developed sequelae, defined as need to follow-up because of direct complications associated to the disease after discharge (24 patients).

Overall, the median age of both groups was similar, most of them children older than 9 years of age, with a majority of male patients. Lower and upper extremities were the most affected anatomic sites, and at the time of evaluation most of them were classified as having moderate envenoming according to the initial signs and symptoms presented (table 2).

\section{Clinical findings and hospitalisation evolution}

No differences between the time for medical evaluation or the time for antivenom administration were

Table 1 Case definition of patients with snakebite envenoming

\begin{tabular}{ll}
\hline No envenoming & Patients with no local or systemic signs or symptoms \\
\hline Mild envenoming & $\begin{array}{l}\text { Local oedema in one or two segments, pain at the bite site, absence of systemic signs or symptoms. } \\
\text { Moderate } \\
\text { envenoming }\end{array}$ \\
$\begin{array}{l}\text { Oedema in three segments, local haemorrhage. Systemic symptoms (bleeding, hypotension) and blood } \\
\text { clotting test alterations }\end{array}$ \\
$\begin{array}{l}\text { Oedema extending to the whole limb, local haemorrhage with necrosis, severe hypotension, blood } \\
\text { clotting alterations, systemic bleeding and, in some cases, acute kidney injury. }\end{array}$ \\
\hline
\end{tabular}


Table 2 Demographic and clinical findings of patients with and without snakebite sequelae

\begin{tabular}{|c|c|c|c|}
\hline & No sequelae $n=50$ & With sequelae $n=24$ & $P$ value \\
\hline Age, months (range) & $113(67.3-130.5)$ & $110(73-130.8)$ & 0.87 \\
\hline Male gender & $34(68)^{\star}$ & $18(75)^{\star}$ & 0.59 \\
\hline Anatomical site of the bite & & & 0.43 \\
\hline Lower extremities & $33(66)$ & $14(58)$ & \\
\hline Upper extremities & $14(28)$ & $10(41.6)$ & \\
\hline Head & $2(4)$ & 0 & \\
\hline Chest & $1(2)$ & 0 & \\
\hline Severity of envenoming & & & 0.095 \\
\hline Mild & $13(26)$ & $3(12.5)$ & \\
\hline Moderate & $36(72)$ & $18(75)$ & \\
\hline Severe & $1(2)$ & $3(12.5)$ & \\
\hline Time to medical evaluation, hours (range) & $2.0(1.0-9.0)$ & $2.0(1.25-5.5)$ & 0.76 \\
\hline Time to administration of antivenom, hours (range) & $2.0(1.0-15.0)$ & $2.0(1.0-6.0)$ & 0.84 \\
\hline \multicolumn{4}{|l|}{ Initial signs and symptoms } \\
\hline Pain & $37(74)$ & $17(70.8)$ & 0.78 \\
\hline Local oedema & $47(94)$ & $24(100)$ & 0.54 \\
\hline Bleeding & $14(28)$ & $10(41.6)$ & 0.29 \\
\hline Bullae formation & $5(10)$ & $4(16.7)$ & 0.46 \\
\hline Local necrosis & 0 & $2(8.3)$ & - \\
\hline \multicolumn{4}{|l|}{ Acute complications presented during hospitalisation† } \\
\hline Infection & $3(6)$ & $9(37.5)$ & 0.0013 \\
\hline Serum sickness & $2(4)$ & $1(4.2)$ & $>0.99$ \\
\hline Compartmental syndrome & $16(32)$ & $20(83.3)$ & $<0.0001$ \\
\hline Need of fasciotomy & $17(34)$ & $21(87.5)$ & $<0.0001$ \\
\hline
\end{tabular}

Categorical data are expressed as frequencies (\%) and analysed using Fisher or $\chi^{2}$ test.

Continuous data are expressed as median (25\%-75\% interquartile range) and analysed using Mann-Whitney rank test or Student's ttest.

Values in bold indicate significant two-sided $p$ values.

${ }^{*}$ Results are presented as number of patients and percentages (in parentheses).

†Acute complications presented during hospitalisation refers to those complications presented during the initial days after snakebite, and not to long-term complications.

significant among groups. Regarding signs and symptoms presented by patients at the time of first evaluation, most of them had locally associated oedema, pain and bleeding as the main clinical features (table 2).

During hospitalisation, some patients presented acute complications that were also analysed. Serum sickness was observed in only three patients among both groups, but local wound infection and clinically diagnosed compartmental syndrome were significantly higher in the group that developed sequelae thereafter (table 2).

\section{Sequelae among patients}

Among the 24 patients with sequelae documented after discharge, scars, functional limitation of the limb affected (meaning complications that diminish or eliminate the regular motor function of an extremity or part of it) and the need of skin graft were the most common ones (table 3). Long-term sequelae included in this study go from mild (hypertrophic scars) to severe complications (amputation). Nevertheless, all of them translated in long-term follow-up and some degree of transitory or permanent disability for all patients.

Table 3 Sequelae description

\begin{tabular}{ll}
\hline Sequelae & $\begin{array}{l}\text { Number of } \\
\text { patients } \\
\text { (frequency) } \\
\mathbf{n = 2 4}\end{array}$ \\
\hline Hypertrophic scar & $16(66.7)$ \\
Functional limitation & $9(37.5)$ \\
Skin graft & $9(37.5)$ \\
Deformity & $2(8.3)$ \\
Amputation & $1(4.2)$ \\
\hline
\end{tabular}

*Results are presented as number of patients and percentages (in parentheses). 
The median follow-up time of these patients in different specialties (plastic and reconstructive surgery, orthopaedic surgery, physiatry, physiotherapy and occupational therapy) due to the sequelae was 25.4 months (5.6-59.4). The frequency and duration of follow-up among these patients varied widely, and it was decided by the specialist according to individual needs and progress in time.

\section{DISCUSSION}

Viperid snakebite envenomings are characterised by prominent local and systemic alterations, some of which may lead to permanent damage to various organs, thus generating long-term sequelae. ${ }^{6}$ Despite the relevance of this aspect of envenomings, there have been few studies focusing on sequelae and the factors that determine their incidence. This single centre study analysed the clinical characteristics and differences among paediatric patients with snakebite envenoming, comparing those with and without long-term sequelae.

The patients of this study presented the typical local and systemic manifestations described for viperid snakebite envenomings, and particularly for those caused by $B$. asper, which inflicts the vast majority of cases in Costa Rica. ${ }^{7}$ Most patients developed envenomings graded as moderate in terms of severity, and all of them received the polyvalent antivenom manufactured in Costa Rica, which is used in the treatment of viperid snakebite envenomings. The incidence of adverse reactions to antivenom administration was low, in agreement with previous studies. ${ }^{8}$ It is recommended that antivenom be administered within the first 3-4hours after the event to decrease the rates of complications, mortality and long-term sequelae. ${ }^{19-11}$ In our cohort, nevertheless, one-third of patients were treated after this recommended period of time, mostly due to delay in transportation from remote rural settings, as shown for several regions in Costa Rica. ${ }^{12}$

Little is known about the risk factors associated with the development of long-term sequelae following snakebites in children. Age and average of time lapsed to first medical evaluation and antivenom administration have been described in other studies as predictors of mortality and morbidity in adults and children. ${ }^{3} 13$ In our study, when analysing the factors associated with the development of sequelae, no significant differences between both groups of patients were observed regarding age, gender, anatomical site of the bite, severity of envenoming, time to reach the hospital and to receive the first dose of antivenom, and local clinical manifestations of envenoming. Thus, despite the fact that previous literature has related late medical care with a higher risk of complications, including lethality, ${ }^{11}$ no significant association between time to reach treatment and incidence of sequelae was observed in our study.
In contrast, infections at the site of the bite and the presence of compartmental syndrome were significantly more prevalent in the long-term sequelae group. Wound infections and compartmental syndrome have been described previously by our group to be associated with severity of enenomings. ${ }^{910}$ Infections are prevalent in envenomings by $B$. asper, ${ }^{8}{ }^{10}$ particularly when there is local tissue damage, since tissue ischaemia and necrosis favour infection by bacteria present in the venom or in the skin of the patient. Venom-induced tissue damage and local infection foster a vicious cycle of tissue necrosis, hence explaining the association between infection and sequelae in our study.

In viperid snakebite envenomings, compartment syndrome is a consequence of extravasation into the interstitial space of muscle tissue, resulting in increments in intracompartmental pressure which, when reaching values of $30-40 \mathrm{~mm} \mathrm{Hg}$, interruption of arterial blood flow, ischaemia and necrosis occurs. Such increase in vascular permeability is due to the direct action of venom components in the microvasculature, but also to the action of endogenous inflammatory mediators synthesised or released in the tissue as a consequence of venom-induced pathology. ${ }^{14}$ Previously, our group has suggested that a cytokine response is associated with severe envenomings in bites by $B$. asper..$^{15}$ Of concern, a high percentage (almost 50\% including both cohorts) of the paediatric patients included in this study developed compartmental syndrome which required surgical decompression, that is, fasciotomy. Thus, the higher incidence of sequelae in children who underwent fasciotomy could be related to pressure-induced tissue damage, or to the consequences of this surgical intervention, especially regarding scar formation. It is necessary to further study the effect of compartment syndrome in these sequelae, and how to reduce its incidence.

Among the group of patients who developed sequelae, we found that the median follow-up time was considerable, exceeding a 2-year period after the event. This finding has social, psychological and institutional implications of various sorts. The children developing sequelae, as well as their families, undergo suffering and limitations, not only physical but also psychological. In addition, the costs for the following-up of the consequences of snakebite envenoming are high, both for the affected people and for the public health system. Management of this neglected tropical disease is very costly, ${ }^{4}$ and the expenses increase considerably when long-term follow-up is needed. This is another aspect of this problem that requires further studies.

Our study has limitations. Patients were enrolled in a referral centre, thus the population of patients are selected to be moderate or severe envenomings, since mild cases are handled in rural hospitals. Therefore, our observations of patients who were not only bitten by a snake but also that required hospitalisation and referral to a specialised centre, can overestimate the prevalence of acute complications, and cannot be extrapolated 
to the rest of the country, where the risk of developing sequelae is likely to be lower. Nevertheless, demographic and several clinical features of both groups (with and without sequelae) were similar. This is a retrospective study; nevertheless, given the long term of the study, the number of patients allowed the analysis of the clinical features associated with the development sequelae.

\section{CONCLUSION}

A 14-year study was conducted describing the clinical presentation among paediatric patients suffering snakebite envenoming with and without sequelae. Our study found that, among the acute complications, infection and compartment syndrome were significantly higher in those patients that further developed long-term sequelae. Given the high personal and healthcare burden that entails the follow-up of these patients, efforts should be carried out to prevent the factors associated with sequelae among the affected population.

Twitter María Luisa Avila-Aguero @maluavi

Acknowledgements We thank Dr Manuel Soto-Martínez for his help in some of the statistical aspects of this paper, for his work and useful thoughts about the manuscript.

Contributors HB-C and Ávila-Agüero conceptualized and designed the study and data collection instruments. They collected data, carried out the initial analyses, drafted and reviewed the manuscript. JMG contributed to the study design and the initial analyses. He critically reviewed the manuscript for intellectual content. $\mathrm{KC}-\mathrm{B}, \mathrm{AS}-\mathrm{F}, \mathrm{RU}-\mathrm{G}$, and $\mathrm{KV}$ collected data, and were in charge of patients during hospitalization and follow up. They reviewed the manuscript. All authors approved the final manuscript as submitted and agree to be accountable for all aspects of the work.

Funding The authors have not declared a specific grant for this research from any funding agency in the public, commercial or not-for-profit sectors.

Competing interests None declared.

Patient consent for publication Not required.

Ethics approval This study was approved by the Bioethical and Research Committee of the National Children's Hospital, CLOBI-HNN, project 001-2015.

Provenance and peer review Not commissioned; externally peer reviewed.

Data availability statement All data relevant to the study are included in the article or uploaded as supplementary information. All data relevant to the study are included in the article or uploaded as supplementary information. If questions or requests for additional information, please contact corresponding author.

Open access This is an open access article distributed in accordance with the Creative Commons Attribution Non Commercial (CC BY-NC 4.0) license, which permits others to distribute, remix, adapt, build upon this work non-commercially, and license their derivative works on different terms, provided the original work is properly cited, appropriate credit is given, any changes made indicated, and the use is non-commercial. See: http://creativecommons.org/licenses/by-nc/4.0/.

\section{ORCID iDs}

Helena Brenes-Chacon http://orcid.org/0000-0002-2207-7450

Rolando Ulloa-Gutierrez http://orcid.org/0000-0002-9157-9227

María Luisa Avila-Aguero http://orcid.org/0000-0002-1979-0431

\section{REFERENCES}

1 Gutiérrez JM, Calvete JJ, Habib AG, et al. Snakebite envenoming. Nat Rev Dis Primers 2017;3:17063.

2 Minghui R, Malecela MN, Cooke E, et al. Who's snakebite envenoming strategy for prevention and control. Lancet Glob Health 2019;7:e837-8.

3 Sankar J, Nabeel R, Sankar MJ, et al. Factors affecting outcome in children with snake envenomation: a prospective observational study. Arch Dis Child 2013;98:596-601.

4 Jayawardana S, Arambepola C, Chang T, et al. Long-Term health complications following snake envenoming. $J$ Multidiscip Healthc 2018;11:279-85.

5 Abubakar SB, Habib AG, Mathew J. Amputation and disability following snakebite in Nigeria. Trop Doct 2010;40:114-6.

6 Warrell D. Snakebites in Central and South America: epidemiology, clinical features and clinical management. The Venomous Reptiles of the Western Hemisphere: Cornell University Press, 2004.

7 Arroyo O, Rojas G. Envenenamiento POR mordedura de serpiente en Costa Rica en 1996: epidemiología Y consideraciones clínicas. Acta Médica Costarricense 1999;41:23-9.

8 Otero-Patiño R, Segura A, Herrera M, et al. Comparative study of the efficacy and safety of two polyvalent, caprylic acid fractionated [lgG and $F\left(a b^{\prime}\right) 2$ ] antivenoms, in Bothrops asper bites in Colombia. Toxicon 2012;59:344-55.

9 Brenes-Chacón H, Gutiérrez JM, Camacho-Badilla K, et al. Snakebite envenoming in children: a neglected tropical disease in a Costa Rican pediatric tertiary care center. Acta Trop 2019;200:105176.

10 Brenes-Chacón H, Ulloa-Gutierrez R, Soriano-Fallas A, et al. Bacterial Infections Associated with Viperidae Snakebites in Children: A 14-Year Experience at the Hospital Nacional de Niños de Costa Rica ${ }^{\dagger}$. Am J Trop Med Hyg 2019;100:1227-9.

11 Tavares AV, Araújo KAMde, Marques MRdeV, et al. The epidemiology of snakebite in the Rio grande do Norte state, northeastern Brazil. Rev Inst Med Trop Sao Paulo 2017;59:e52.

12 Hansson E, Sasa M, Mattisson K, et al. Using geographical information systems to identify populations in need of improved accessibility to antivenom treatment for snakebite envenoming in Costa Rica. PLoS Negl Trop Dis 2013;7:e2009.

13 da Silva Souza A, de Almeida Gonçalves Sachett J, Alcântara $\mathrm{JA}$, et al. Snakebites as cause of deaths in the Western Brazilian Amazon: why and who dies? deaths from snakebites in the Amazon. Toxicon 2018;145:15-24.

14 Gutiérrez JM, Rucavado A, Chaves F, et al. Experimental pathology of local tissue damage induced by Bothrops asper snake venom. Toxicon 2009;54:958-75.

15 Avila-Agüero ML, París MM, Hu S, et al. Systemic cytokine response in children bitten by snakes in Costa Rica. Pediatr Emerg Care 2001:17:425-9. 